\title{
Android Application-Based Interactive Services for Diabetes Mellitus Patients
}

\author{
Rara Warih Gayatri $1^{1, *}$ Septa Katmawanti ${ }^{1}$ Hartati Eko Wardani ${ }^{1}$ \\ Prof. Dr. Low Wah Yun ${ }^{2}$ \\ ${ }^{1}$ Department of Public Health, Universitas Negeri Malang, Malang, East Java, 65112, Indonesia \\ ${ }^{2}$ Faculty of Medicine University of Malaya, Kuala Lumpur, 50603, Malaysia \\ *Corresponding author. Email: rara.warih.fik@um.ac.id
}

\begin{abstract}
Android applications have been developed for an early detection of type 2 Diabetes Mellitus (DM). However, its development has yet to be interactive and has not involved experts, such as health consultants. The purpose of this study is to develop an interactive service and a product design based on Android application for people with DM. This study employs research and development $(\mathrm{RnD})$ design. The research phase consists of situation analysis, data collection, product design, expert validation, product revision, product tryout and final revision. Expert validation is carried out by android application experts and material experts. The try-out was conducted at Janti Health Center in Malang on subjects aged 45-54 years in June 2019. A small group try-out was conducted on 10 subjects who did not suffer from type $2 \mathrm{DM}$. The large group try-out in subjects with type $2 \mathrm{DM}$ involved 30 people. The research instrument was a questionnaire. Data analysis involved descriptive quantitative in the form of percentages. Most of the research subjects are aged between 50-59 years old and 60-69 years old with the percentage of 35\%. In this research, the female respondents are in a larger number compared to the male respondents, which amounts to $80 \% .58 \%$ of the subjects are employed, while the $43 \%$ are unemployed. Of all the subjects, $40 \%$ have a level of education equals to Junior High School or Secondary School. Based on the analysis result of the small group, it is known that $74 \%$ of the subjects stated that the application is clear, easy, and suitable to be used. Meanwhile, the analysis result on the target group shows that $77 \%$ of the respondents stated that the application is clear, easy, and suitable to be used. The application is deemed to be worthy to be used by a various kinds of people in the society, no matter what their ages, genders, occupations, and education backgrounds are.
\end{abstract}

Keywords: diabetes mellitus, interactive services, android application

\section{INTRODUCTION}

Diabetes Melitus (DM) is a non communicable or non contagious disease that is marked with the increase of sugar-blood levels as the result of the interactions between the factors of genetic risks, environments, and so on [1]. The prevalence of DM always significantly increase anually [2]. The changes of epidemiology transmission patterns of DM in any ages add to the burden of diseases in the world. (2, 3, $4)$. The increase in the prevalence happens mostly in developing countries [5]. In fact, Indonesia is one of the ten countries that has the biggest amount of DM sufferers [6].

According to the data of International Diabetes Federation (IDF), there were 382 million DM sufferers in the year of 2013, and the number increased on 2017 to be 425 millions of people, and it is predicted to increase even more on 2035 to be 592 million sufferers $(7,8)$. According to Padros et.al, $90 \%$ of DM cases in the world is the second type of diabetes [9], [10]. Moreover, the result of the Riset Kesehatan Dasar/RISKESDAS (Basic Health Research) in 2013 also shows the doubled increase compared to 2007 [11]. In the year of 2030, the sufferers of DM in Indonesia will increase to be 21,3 million people, according to the Indonesian Ministy of Health. The increasing prevalence of DM is expected to result in complications, such as nouropathy and nefropathy, so that the burden on the health sector would be increasing as well $(12,9)$. The number of DM cases that are not diagnosed before and only known when complications have occurred makes DM often referred to as the silent killer [13]. 
The number of undiagnosed DM patients in 2013 was 175 million out of $382 \mathrm{DM}$ sufferers [7], while $0.6 \%$ or about 1 million people aged over 15 years who felt symptoms of DM but had not yet been diagnosed with certainty were recorded in Indonesia in the same year [10]. Padros et al stated that one of the contributors to the increased prevalence of DM is the $5-10 \%$ total prediabetes population each year [9]. According to the data at Cipto Mangun Kusumo Hospital in Jakarta, 54\% of people with DM have experienced retinopathy or proteinuria complications when they arrive at the hospital. This shows that there is a lack of integrated services involving many disciplines.

The improvement of public health services must be done to compensate for the high number of DM sufferers today [14]. Controlling risk factors in both key populations and at-risk populations is one way to prevent this increase in prevalence [15]. Alaqeel believes that this can be prevented by developing an early detection program for DM so that the number of DM sufferers can be controlled [16]. In this digital era, one form of intervention that can be done is the approach through digital media, which is currently popular with the public, namely smartphones [17]. The development of a DM early detection application on Android to help people know their risk for being infected by DM is now in progress [18]. However, in the process of its development, some updates are still needed so that the application can be used by all levels of society.

\section{MATERIALS AND METHOD 2.1. Design}

This research uses the Research and Development method. Broadly speaking, this method is divided into two major parts, namely product design and the product of Android application itself. For the first year, the $\mathrm{RnD}$ method is focusing on the product design, while the second year is focusing on testing the product design to the targets. The procedure of this study adapted Sugiyono's development model [19] with a few modifications, which are illustrated in Figure 1.

Broadly speaking, the steps of this study are divided into 3 macro stages, namely the preliminary study stage, the development stage, and the trial stage. In the preliminary study, a literature review was conducted to identify the need for an android application for DM disease services, then a data analysis was performed. At the development stage, the researcher designs the application, and the development is then validated by media and material experts. Meanwhile, the implementation of the android application to the research subjects is carried out at the trial stage, and ultimately the results will be measured.
The product design chart in this study is illustrated in Figure 2.

The review of the application system used for DM disease interactive services is made using the Android operating system and is designed for smartphones. This application can run on android API level 8 (Android 2.2 Froyo) to API level 19 (Android 4.4 KitKat). Specifically, the software that is used to develop the Android application for early detection of DM disease is CorelDraw X6 and Adobe Flash Professional CS6.

\subsection{Population and Study Setting}

The product development trial was conducted at the Public Health Center (PUSKESMAS/Pusat Kesehatan Masyarakat) in Janti, Malang, on the visitors aged 45-54 years in June 2019. Previously, a small group trial was conducted on 10 randomly selected people. The sampling technique in this study uses quota sampling, with a minimum sample size of 30. This is due to the limited research time.

\subsection{Data Collection}

\subsubsection{The Collection of Validation Data}

Product design validation is a stage carried out by experts to provide an assessment of the product. Each expert was asked to rate the design so that the weaknesses and strengths could be further identified. The experts in question consisted of IT experts and content experts. In the design validation process, the instruments needed are in the form of a questionnaire containing a number of close-ended questions where answers to the questions are provided. The measurement scale used as a reference is the Likert scale. Then, the experts will provide answers by crossing $(\mathrm{X})$ on the answer they think as appropriate.

\subsubsection{The Collection of Trial Data}

The trial instrument is a questionnaire. The questionnairre consists of a set of questions regarding the usage of the android application to detect DM disease, and whether or not they fulfill the users expectations.

\subsection{Data Analysis}

\subsubsection{Experts Validation}

The assessment by the experts are adjusted to the appropriate numbers. The range of the score is as follows:

$\begin{array}{ll}\mathrm{a} & =\text { Very suitable } \\ \mathrm{b} & =\text { Suitable } \\ \mathrm{c} & =\text { Suitable enough }\end{array}$


$\mathrm{d}=$ Unsuitable

The next assessment score is based on the analysis using a simple descriptive quantitative analysis, which is the calculation of percentage. The scoring category refers to the category of assessment:

$\begin{array}{ll}76-100 \% & =\text { Very worthy } \\ 51-75 \% & =\text { Worthy } \\ 26-50 \% & =\text { Worthy enough } \\ 0-25 \% & =\text { Not worthy }\end{array}$

\subsubsection{Trial}

The test data analysis technique used is a simple descriptive data analysis technique, which is percentage. The value obtained from each indicator, i.e. the total value of each indicator, is calculated by the maximum amount and multiplied by $100 \%$, more details can be seen in the calculation below.

$$
P=\frac{f}{N} \times 100 \%
$$

Notes:

$\mathrm{P}=$ Percentage

$\mathrm{f}=$ the frequency that is being sought or the score obtained

$\mathrm{N}=$ Number of cases or maximum score

Furthermore, based on the percentage value, the results of user responses are determined, referring to the categories according to Khabibah (2006) in Wulandari and Waryanto (2012), namely:

$$
\begin{array}{ll}
85 \% \geq \text { responds } & =\text { Very positive (very high) } \\
70 \% \leq \text { responds }<85 \% & =\text { Positive (high) } \\
50 \% \leq \text { responds }<70 \% & =\text { Negative (low) } \\
\text { responds }<50 \% & =\text { Very negative (Very low) }
\end{array}
$$

\section{ETHICAL ASPECTS}

Written informed consent was given to all participants. The study was approved by the Local Ethics Committees at Universitas Brawijaya Malang, Indonesia.

\section{RESULTS}

\subsection{The Frequency Distribution of Respondents \\ 4.1.1.The Frequency Distribution of Respondents based on Ages}

The respondents of this study have an age range of 30-79 years. The age group with the highest number of respondents is the age group of 50-59 years and 60-69 years with a percentage of $35 \%$ each. Meanwhile, the lowest age group is 70-79 years, which is 5\%. For further information, see Table 1.

Table 1. The Frequency Distribution of Respondents based on Ages

\begin{tabular}{|c|c|c|}
\hline Age Group & $\mathbf{n}$ & \% \\
\hline $30-39$ & 4 & 10 \\
\hline $40-49$ & 6 & 15 \\
\hline $50-59$ & 14 & 35 \\
\hline $60-69$ & 14 & 35 \\
\hline $70-79$ & 2 & 5 \\
\hline Total & $\mathbf{4 0}$ & $\mathbf{1 0 0}$ \\
\hline
\end{tabular}

\subsubsection{The Frequency Distribution of Respondents based on Genders}

There were more female respondents in this study than male respondents. The percentage of female respondents was $80 \%$, while male respondents were $20 \%$. A clearer description of the frequency distribution of respondents by sex can be seen in Table 2.

Table 2. The Frequency Distribution of Respondents based on Genders

\begin{tabular}{|c|c|c|}
\hline Sex & $\mathbf{n}$ & \% \\
\hline Male & 8 & 20 \\
\hline Female & 32 & 80 \\
\hline Total & $\mathbf{4 0}$ & $\mathbf{1 0 0}$ \\
\hline
\end{tabular}

\subsubsection{The Frequency Distribution of Respondents based on Employment Status}

As many as $58 \%$ of respondents in this study were workers, and $43 \%$ of respondents did not work. A clearer description of the frequency distribution of respondents based on employment status can be seen in Table 3 .

Table 3. The Frequency Distribution of Respondents based on Occupations

\begin{tabular}{|c|c|c|}
\hline Employment Status & n & \% \\
\hline Employed & 17 & 43 \\
\hline Unemployed & 23 & 58 \\
\hline Total & $\mathbf{4 0}$ & $\mathbf{1 0 0}$ \\
\hline
\end{tabular}

\subsubsection{The Frequency Distribution of Respondents based on Level of Education}

Based on the results of the study listed in Table 4 regarding the frequency distribution of respondents based on their level of education, it is known that $40 \%$ of respondents have an equivalent level of junior high school. Whereas respondents who are in University level were $10 \%$, and respondents who have an elementary and high school education level were $25 \%$ each. 
Table 4. The Frequency Distribution of Respondents based on Level of Education

\begin{tabular}{|c|c|c|}
\hline Education Level & n & \% \\
\hline Elementary & 10 & 25 \\
\hline Secondary & 16 & 40 \\
\hline High School & 10 & 25 \\
\hline University & 4 & 10 \\
\hline Total & $\mathbf{4 0}$ & $\mathbf{1 0 0}$ \\
\hline
\end{tabular}

\subsection{User Evaluation Result}

\subsubsection{The Trial Result of the Small Group} (Non DM)

Based on the results of the analysis in small groups, it is known that $74 \%$ of the respondents stated that this application is clear, easy, and suitable for use while $25 \%$ of the respondents stated that this application is very clear, very easy and very suitable for use. The results of the small group trial questionnaire can be seen in Table 5 .

Table 5. The Trial Result of the Small Group (Non DM)

\begin{tabular}{|c|c|c|}
\hline Category & n & \% \\
\hline Very Clear & 2 & 25 \\
\hline Clear & 7 & 74 \\
\hline Unclear & 1 & 1 \\
\hline Very Unclear & 0 & 0 \\
\hline Total & $\mathbf{1 0}$ & $\mathbf{1 0 0}$ \\
\hline
\end{tabular}

\subsubsection{The Trial Result of the Target Group}

Based on the analysis of the target group, $77 \%$ of the respondents stated that this application was clear, easy and appropriate to use, while $17 \%$ of respondents stated that this application was very clear, very easy and very suitable for use. The results of the target group trial questionnaire can be seen in Table 6 .

Table 6. The Trial Result of the Target Group

\begin{tabular}{|c|c|c|}
\hline Category & $\mathbf{n}$ & \% \\
\hline Very clear & 5 & 17 \\
\hline Clear & 23 & 77 \\
\hline Unclear & 2 & 6 \\
\hline Very Unclear & 0 & 0 \\
\hline Total & $\mathbf{3 0}$ & $\mathbf{1 0 0}$ \\
\hline
\end{tabular}

\subsubsection{Overall Evaluation Results}

Based on the table above, $78 \%$ of the respondents stated that this application was clear, easy, and suitable for use, while $19 \%$ of respondents stated that this application was very clear, very easy, and very suitable for use. The results of the target group trial questionnaire can be seen in Table 7 .
Table 7. Overall Evaluation Results

\begin{tabular}{|c|c|c|}
\hline Category & n & \% \\
\hline Very Clear & 8 & 19 \\
\hline Clear & 31 & 78 \\
\hline Unclear & 2 & 5 \\
\hline Very Unclear & 0 & 0 \\
\hline Total & $\mathbf{4 0}$ & $\mathbf{1 0 0}$ \\
\hline
\end{tabular}

\section{DISCUSSION}

In product trials related to the aspects of appearance, content, usefulness, and convenience, the results showed that the majority of the respondents rated this application as clear, easy, and suitable for use as an early detection tool for DM. This application is considered as an appropriate application to be used by various groups of people of different ages, genders, employment status, and education levels. This shows that the DM early detection application can be used by users with various backgrounds.

Demographic factors are very influential in the success of product output, because this product, which was developed on a smartphone, plays an important role in educating its users, as well as recording data to find out how much the user is at risk of DM [20]. Therefore, to find out how much the ability of this application to provide accurate and meaningful information to users, it is necessary to validate before testing the target [21]. One aspect that is needed to support changes in healthier lifestyles through smartphone applications is the available features and user personal factors [22].

Diseases' early detection applications on smartphone devices have now been widely developed [23], [24]. Among the 50,000 applications on the available devices, some can be downloaded and used at no charge [23]. One example of this innovation is the DM early detection application developed on the Android system by applying different methods and several tests to determine the risk factors [25]. The American Diabetes Association (ADA) has created an online calculator to calculate the DM risk of its users and can only be accessed through the ADA official website before the Android-based application is created, where the online calculator displays a few simple questions and the accumulation of answer points will show how many factors of risks held by these users [26].

The development of early disease detection systems is currently mostly done on android systems [25], [27]. This is associated with a higher number of Android users than iOS system users, so the application range becomes wider [28]. Many things must be considered in developing an android application even though it has a broad reach [29]. Criteria that must be met by health applications 
include ease and acceptance, portability, ease of operation, and ease of learning on existing information [30].

Fijacko et.al argues that the application design that must be considered by health application developers includes visualization, font size, and button size [25]. Associated with the concept of delivering messages, the appearance of the application is one important factor that must be considered. To facilitate the delivery of messages, a combination of elements that can function together is certainly very necessary [16]. The research that has been carried out by Teo et.al shows that the users of health early detection applications want applications that have features that are easy to use, easy to operate, and have social connectivity. Another thing to consider besides the appearance of the health screening application is its ability to securely store the user's personal information and medical history [31].

The development of this application aims to globally suppress the morbidity, mortality, and complications due to DM [32]. The increase in DM complications is caused by the majority of patients who have not been diagnosed before (by 50\%, according to the study of Venugopal, et al.) [33]. The existence of this innovation is expected to provide an input for health policies related to non-communicable diseases (NCDs), especially DM [25]. Reducing health disparities is certainly easier to implement when implementing multidisciplinary interactions between policy strategies and digital technology [27]. This strategy is considered effective because it does not require high costs to access the health screening application widely [28]. In addition, the application has the potential to prevent the burden of chronic disease in the world because of its effectiveness in improving the degree of public health without the constraints of distance and time [30], [34], [35]. The development of early DM detection applications on smartphones can influence the prevention of type 2 DM through the promotion of a healthier lifestyle and the special attention given to the prevention of DM complications [36]. Also, the application of DM early detection will help the public to find out how much risks of DM potential they have [37].

\section{CONCLUSION}

This study found that majority of respondents stated that the application was clear, easy, and suitable to be used. The application is deemed to be worthy to be used by a various kinds of people in the society, no matter what their ages, genders, occupations, and education backgrounds are.

\section{AUTHORS' CONTRIBUTIONS}

RWG, SK, HEW contributed to concept, design the study, data collection, data analysis, and writing the manuscript. Meanwhile, LWY contributed to the data analysis and review.

\section{ACKNOWLEDGMENTS}

The authors express the gratitude to Universitas Negeri Malang for giving financial support to this study.

\section{REFERENCES}

[1] H. Du et al., "Fresh fruit consumption in relation to incident diabetes and diabetic vascular complications : A 7-y prospective study of 0.5 million Chinese adults," vol. 300, pp. 1-19, 2017.

[2] A. Sofía, J. Andreassen, J. Halling, and P. Grandjean, "Journal of Clinical \& Translational Endocrinology Prevalence of prediabetes and type 2 diabetes in two non-random populations aged $44-77$ years in the Faroe Islands," J. Clin. Transl. Endocrinol., vol. 16, no. March, p. 100187, 2019.

[3] S. S. Hui, G. P. Hui, and Y. J. Xie, “Association between Physical Activity Knowledge and Levels of Physical Activity in Chinese Adults with Type 2 Diabetes," pp. 1-15, 2014.

[4] A. E. Uloko, B. M. Musa, and M. A. Ramalan, "Prevalence and Risk Factors for Diabetes Mellitus in Nigeria: A Systematic Review and Meta-Analysis," Diabetes Ther., vol. 9, no. 3, pp. 1307-1316, 2018.

[5] B. Feng, C. Huang, J. Cao, Z. Dong, F. Liu, and L. Ji, "ScienceDirect Diabetes awareness, treatment, control rates and associated risk factors among Beijing residents in 2011: A cross-sectional survey," Chronic Dis. Transl. Med., vol. 2, no. 3, pp. 147-158, 2016.

[6] L. Mihardja, U. Soetrisno, and S. Soegondo, "Prevalence and clinical profile of diabetes mellitus in productive aged urban Indonesians," J. Diabetes Investig., vol. 5, no. 5, pp. 507-512, 2014.

[7] IDF, IDF Diabetes Atlas. 2015.

[8] IDF, IDF Diabetes Atlas Eighth edition 2017. 2017.

[9] A. Ferrer, F. Formiga, O. Cunillera, T. Badia, X. Corbella, and O. S. Group, "Prevalence of Prediabetes and Associated Factors in the Oldest Old . A Cross Sectional Study in the Octabaix 
Cohort * ria Padr o Gl o," vol. 11, pp. 90-94, 2017.

[10] Kemenkes RI, "Situasi dan Analisis Diabetes," Pusat Data dan Informasi Kementerian Kesehatan RI. p. 2, 2014.

[11] Badan Penelitian dan Pengembangan Kesehatan, "Riset Kesehatan Dasar (RISKESDAS) 2013," Lap. Nas. 2013, pp. 1-384, 2013.

[12] I. Arikpo et al., "Development of a Mobile Software Tool for Diabetes Diagnosis," vol. 5, no. 3, pp. 1-8, 2018.

[13] A. H. Al-saeed et al., "An Inverse Relationship Between Age of Type 2 Diabetes Onset and Complication Risk and Mortality: The Impact of Youth-Onset Type 2 Diabetes," vol. 39, no. May, pp. 823-829, 2016.

[14] D. Preuveneers, Y. Berbers, and W. Joosen, "The Future of Mobile E-health Application Development: Exploring HTML5 for Contextaware Diabetes Monitoring," Procedia Procedia Comput. Sci., vol. 21, pp. 351-359, 2013.

[15] I. S. Okosun and R. Lyn, "Prediabetes awareness , healthcare provider' $\mathrm{s}$ advice, and lifestyle changes in American adults," Int. J. Diabetes Mellit., vol. 3, no. 1, pp. 11-18, 2015.

[16] A. A. Alaqeel, "International Journal of Pediatrics and Pediatric diabetes in Saudi Arabia: Challenges and potential solutions . A review article," Int. J. Pediatr. Adolesc. Med., no. xxxx, 2019.

[17] A. Sophie, T. Thomsen, T. Jensen, C. Schiøtz, H. Langberg, and I. Egerod, "Journal of Clinical \& Translational Endocrinology The influence of diabetes distress on digital interventions for diabetes management in vulnerable people with type 2 diabetes: A qualitative study of patient perspectives," J. Clin. Transl. Endocrinol., vol. 9, pp. 41-47, 2017.

[18] Gayatri, R.W. "Development Of Android-Based Applications For Early Detection Diabetes Mellitus.” 2018.

[19] Lukiati Komala, Evi Novianti, Priyo Subekti, "STRATEGI PEMILIHAN MEDIA PROMOSI KESEHATAN DALAM PENANGGULANGAN HIV/AIDS DI KABUPATEN GARUT" Acta diurnA, Vol 10 No . 2, 34-43, 2014.

[20] A. Saleh, M. Mosa, I. Yoo, and L. Sheets, "A Systematic Review of Healthcare Applications for Smartphones," BMC Med. Inform. Decis. Mak., vol. 12, no. 1, p. 1, 2012.

[21] C. L. Ventola, "Mobile Devices and Apps for Health Care Professionals : Uses and Benefits," vol. 39, no. 5, pp. 356-364, 2014.

[22] D. D. C. Id, K. Robinson, J. Forbes, and S. Hayes, Experiences of mobile health in promoting physical activity: A qualitative systematic review and meta-ethnography. 2018.

[23] K. Yousaf et al., "Mobile-Health Applications for the Efficient Delivery of Health Care Facility to People with Dementia ( PwD ) and Support to Their Carers : A Survey," vol. 2019, 2020.

[24] S. C. Mathews, M. J. Mcshea, C. L. Hanley, A. Ravitz, A. B. Labrique, and A. B. Cohen, "Digital health : a path to validation," npj Digit. Med., no. April, pp. 1-9, 2019.

[25] N. Fijacko, P. P. Brzan, and G. Stiglic, "Mobile Applications for Type 2 Diabetes Risk Estimation : a Systematic Review," 2015.

[26] H. Bang, A.M. Edwards, A.S.Bomback, C.M. Ballantyne, D. Brillion, M.A. Callahan, S.M. Teusch, A.S. Mushlin and L.M. Kern, "A patient self-assessment diabetes screening score," vol. 151, no. 11, pp. 775-783, 2013.

[27] G. N. Graham, M. Ostrowski, and A. B. Sabina, "Population health-based approaches to utilizing digital technology: a strategy for equity," $J$. Public Health Policy, vol. 37, no. 2, pp. 154166.

[28] C. Hou, B. Carter, J. Hewitt, T. Francisa, and S. Mayor, "Do Mobile Phone Applications Improve Glycemic Control ( $\mathrm{HbA} \mathrm{1c}$ ) in the Selfmanagement of Diabetes? A Systematic Review , Meta-analysis , and GRADE of 14 Randomized Trials," vol. 39, no. November, pp. 2089-2095, 2016.

[29] K. L. Masconi, T. E. Matsha, R. T. Erasmus, and A. P. Kengne, "Recalibration in Validation Studies of Diabetes Risk Prediction Models : A Systematic Review," pp. 347-369, 2015.

[30] S. H. Guo, H. Chang, and C. Lin, "Computers in Industry Impact of Mobile Diabetes Self-Care System on patients' knowledge, behavior and efficacy," Comput. Ind., vol. 69, pp. 22-29, 2015.

[31] C. H. Teo, C. J. Ng, and A. White, "What Do Men Want from a Health Screening Mobile App ? A Qualitative Study,”pp. 1-17, 2017.

[32] G. Johanna, M. Vandersmissen, and L. Godderis, 
"EVALUATION OF THE FINNISH DIABETES RISK SCORE ( FINDRISC ) FOR DIABETES SCREENING IN OCCUPATIONAL HEALTH CARE," vol. 28, no. 3, pp. 587-591, 2015.

[33] V. Venugopal, K. Selvaraj, A. Majumdar, P. Chinnakali, and G. Roy, "Opportunistic screening for diabetes mellitus among adults attending a primary health center in Puducherry," vol. 4, no. 9, pp. 0-5, 2015.

[34] L. F. Garabedian, D.Ross-Degnan, and J. F. Wharam, "Mobile Phone and Smartphone Technologies for Diabetes Care and SelfManagement," vol. 15, no. 12, 2019.

[35] A. C. Gao, L. Zhou, Z. Liu, and B. Bowers, "Mobile application for diabetes selfmanagement in China: Do they fit for older adults ?," Int. J. Med. Inform., 2017.

[36] A. Verdejo-Garcia et al., "Social stress increases cortisol and hampers attention in adolescents with excess weight," PLoS One, vol. 10, no. 4, pp. 1-13, 2015.

[37] R. Budi and E. Irwansyah, "The Early Detection of Diabetes Mellitus ( DM ) Using Fuzzy Hierarchical Model," Procedia - Procedia Comput. Sci., vol. 59, no. Iccsci, pp. 312-319, 2015. 